\title{
An Empirical Study on the Linkage between SSE 50 Stock Index Futures and Stock Index Spot
}

\author{
Chen $\mathrm{Jia}^{1, \mathrm{a}}$, Chen Xiaoqian ${ }^{2, \mathrm{~b}^{*}}$ \\ ${ }^{1}$ Beijing Forestry University(No.)35 East Qinghua Road Haidian District, Beijing 100083, China \\ ${ }^{2}$ Beijing Forestry University(No.)35 East Qinghua Road Haidian District, Beijing 100083, China \\ a812639571@qq.com, bchenxiaoqian@bjfu.edu.cn
}

Keywords: SSE 50 stock index futures, Price discovery, Granger causality test.

\begin{abstract}
In this paper, the daily data of SSE 50 stock index futures and SSE 50 index in the past two years from April 16, 2015 to March 16, 2017 are selected as the research object to study the lead relationship between SSE 50 stock index futures and corresponding stock spot price with the methods of co-integration test, Granger causality test, impulse response and variance decomposition etc. The results show that SSE 50 stock index future has a one-way effect on SSE 50 index, and SSE 50 stock index future has reflected the price discovery function.
\end{abstract}

\section{Introduction}

SSE 50 stock index future is listed for transaction on April 16, 2015, which enriched the stock index futures market in China. The launch of stock index futures not only adds a new risk-avoiding tool for investors and improves the utilizing efficiency of capital, but also helps to further improve the structure of capital market in China and enriches the types of financial derivatives. Up to now, stock index futures market in China includes three trading varieties that is CSI 300 stock index futures, SSE 50 stock index futures and CSI 500 stock index futures.

SSE 50 stock index futures listed trading has great practical significance. First, it helps to enhance the fluidity of blue chip stocks, stabilizes the value center of the blue chip, promotes the construction of blue chip market, improves shareholding confidence of the investors, and achieves long-term stable development of the stock market; second, it is conducive to the full play of value investment function of institutional investors. Third, it can cooperate better with SSE 50ETF options to provide effective hedging means for option market makers. The lead relationship between SSE 50 stock index futures and spot market price is studied in this paper in order to provide theoretical basis for investors to avoid risks and improve the stock index futures market in China.

\section{Analysis on the Trend and Correlation of SSE 50 Stock index Futures and SSE 50 Index in China}

SSE 50 stock index futures market taking SSE 50 stock index as subject trades on expected price level of SSE 50 index and the transaction code is IH. Being different from CSI 300 taking large-cap share of the two stock markets as sample and CSI 500 taking small-cap stocks of the two stock markets as sample, 50 stocks of the most representative with big size and good liquidity composing sample stocks based on scientific and objective method are selected for SSE 50 to comprehensively reflect the overall situation of a large number of the most influential high-quality market enterprises in Shanghai securities market. The constituent stocks of SSE 50 index are selected mainly from the financial, real estate, energy and other pillar industries, including the large state-owned banks, non bank finance, large state-owned enterprises such as industrial and Commercial Bank of China, China life and CRRC cooperation limited etc. which are large enterprises concerning the national economy and people's livelihood and are the representative of high-quality blue chips. 
Throughout data from April 16, 2015 to March 23, 2017, it can be seen that the trend of SSE 50 index futures price tends to be consistent with that of the spot market price in a long term and there may be a long-term stable relationship between them.

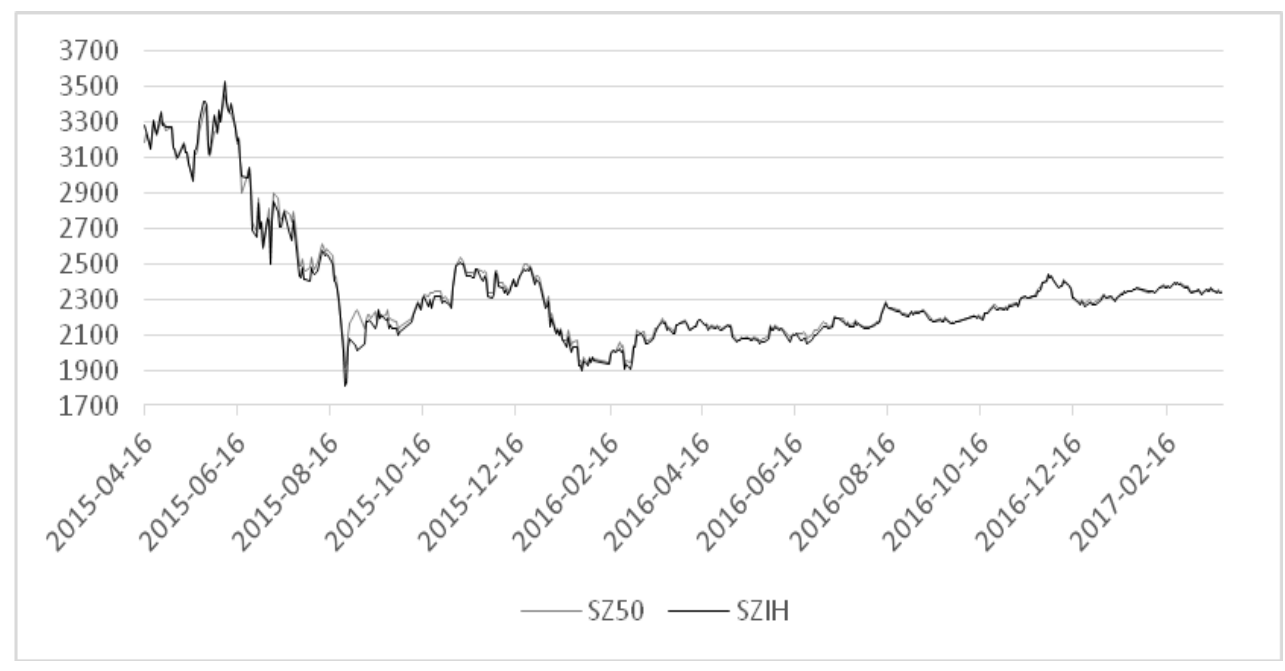

Fig. 1. Trend chart of SZ50 and SZIH from 2015 to 2017.

In theory, due to the futures trading is a contract transaction for forward delivery of goods carried out in public, there is a large number of market supply and demand information centralized in this market including almost all the factors affecting the changes of supply and demand relationship of futures products, and futures trading process actually can comprehensively reflect the expectation of the supply and demand sides on trends of changes of supply and demand relationship and prices, futures price has the characteristics of continuity, openness and expectation. If the operation of the futures market is effective, the futures price has a guiding effect on the spot price, which is the price discovery function of the futures market.

\section{An Empirical Analysis of the Correlation between SSE 50 Stock Index Futures and SSE 50 Index}

3.1 Index Selection and Data source. The daily data of the SSE 50 index closing price and SSE 50 index stock index futures closing price from April 16, 2015 to March 23, 2017 are selected as the research object in this paper. Generally speaking the contract volume instant of the present month is the largest and is the main contract, so the continuous contracts instant of the present month which are more representative are selected as the object of the study of SSE 50 stock index futures. Data sources are form China Securities Index Cooperation and China Financial Futures Exchange, collecting through the wind database. The Shanghai Stock Exchange 50 index is expressed in SZ50 and Shanghai Stock Exchange 50 index futures index is expressed in SZIH in this paper.

3.2 Descriptive Statistical Analyses. Descriptive statistical analyses are carried out on the selected daily data from April 16, 2015 to March 23, 2017. The descriptive results show that the standard deviation of stock index futures is larger than that of the corresponding spot, which means the volatility of stock index futures is more severe. It can be seen that SZIH are more vulnerable to external factors than the SZ50.

3.3 Unit Root Test. The ADF test values of the original sequence of variable SZ50 and SZIH are greater than the critical value of $10 \%$, which means the original sequence of SZ50 and SZIH is not stable, so unit roof test is carried out again on the first-order difference sequence of SZ50 and SZIH and that the $\mathrm{ADF}$ statistics of the two sequences after the difference are less than the critical value under significance level of $1 \%$, which means the sequence after the difference is stable. That is, both SZ50 and SZIH are integrated of order I (1).

3.4 Co-integration Test. Based on the above test, it can see that the two sets of variables after difference are integrated of the same order, so the co-integration test can be carried out to test whether there is a long-term stable equilibrium relationship between the two. 
Table 1. Results of co-integration test.

\begin{tabular}{ccccc}
\hline $\begin{array}{c}\text { Hypothesized No. of } \\
\text { CE(s) }\end{array}$ & Eigenvalue & Trace Statistic & 0.05 Critical Value & Prob.** \\
\hline None $*$ & 0.303075 & 247.0719 & 15.49471 & 0.0001 \\
\hline At most $1 *$ & 0.153677 & 78.08797 & 3.841466 & 0 \\
\hline
\end{tabular}

According to the results of Table 1, we can reject the null hypothesis under significance level of $5 \%$ with rejection of no more than one co-integration hypothesis, which means there are at least 2 co-integration relationships between them. That is, there is a co-integration relationship namely a long-term equilibrium relationship between SZ50 and SZIH under the significance level of 5\%.

3.5 Granger Causality Test. There is a co-integration relationship between SZ50 index and SZIH, which only shows that there is a long-term equilibrium relationship between the two variables. Whether there is a causal relationship or not, the further testing is required. The following results are obtained by Granger causality test with Reviews 8.0 as shown in Table 2 .

Table 2. Results of granger causality test.

\begin{tabular}{ccc}
\hline Original hypothesis & F statistics & Probability \\
\hline $\begin{array}{c}\text { SZIH is not Granger cause of } \\
\text { SZ50 }\end{array}$ & 5.78379 & 0.0166 \\
\hline $\begin{array}{c}\text { SZ50 is not Granger cause of } \\
\text { SZIH }\end{array}$ & 0.25693 & 0.6125 \\
\hline
\end{tabular}

Under the hypothesis that SZIH is not Granger cause of SZ50, the F statistic is greater than the critical level of 5\%, so the original hypothesis is rejected, which means SZIH is the Granger cause of SZ50, and the results of the test accept the hypothesis that SZ50 is not the Granger cause of SZIH. This demonstrates that the changes of SZIH will cause changes in SZ50 and the changes SZ50 can not cause the changes in the corresponding stock index futures index.

3.6 Impulse Response Function. The impulse response function can be drawn to fully reflect the dynamic effects between variables. Impact responses of each variable in the model are observed with the passage of time in the impulse response function which captures the complex and dynamic relationships among variables. The results of impulse response function obtained by eviews8.0 software are shown in Figure 2.
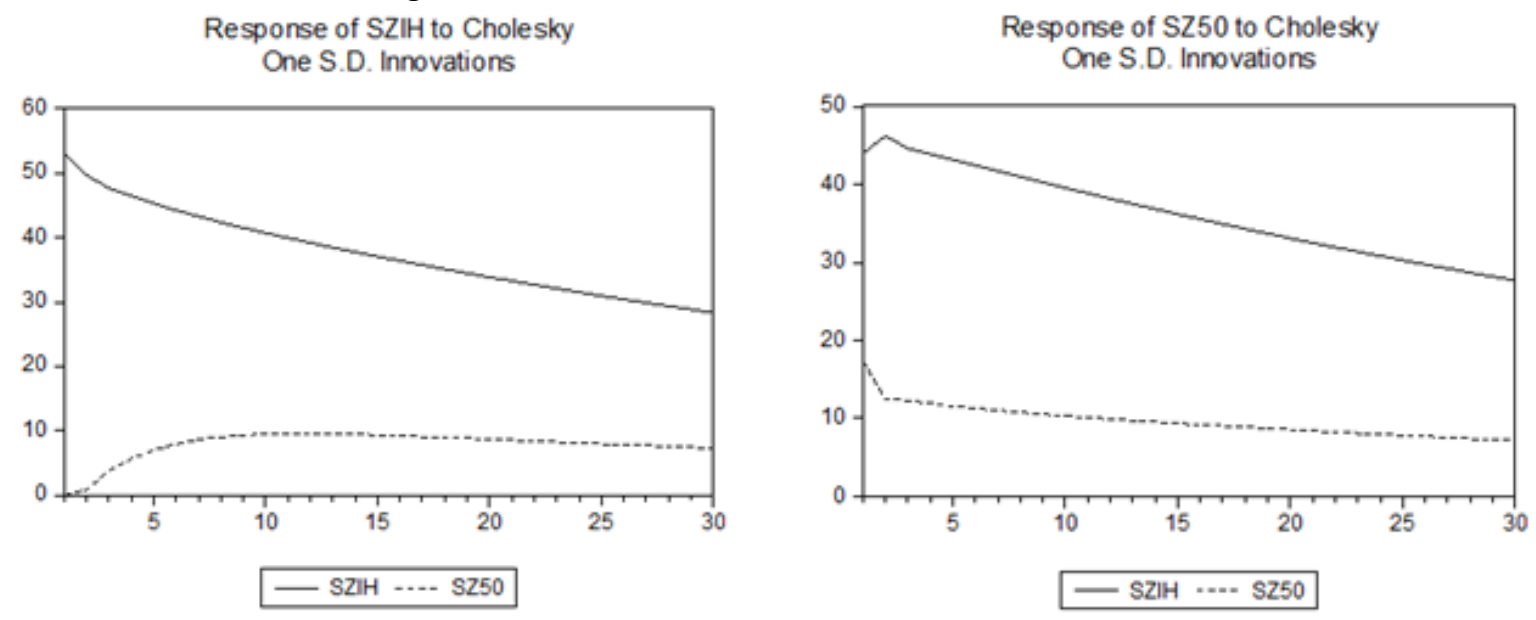

Fig. 2. Effect of impulse response.

The impact periods referred in this paper is 30 periods The first picture shows the response of SZIH, which is subject to the impact of standard deviation information of SZIH and SZ50, and the second picture shows the response of SZ50 to the impact of standard deviation from the spot market. After study on the figure, it can be seen that SZIN shows a strong reaction to the impact of standard deviation information from its own. As for the impact of the standard deviation information from the spot market, SZIH shows weak reaction, the reaction of the first period is 0 , and then the reaction 
gradually increases and reaches its peak of $9.53 \%$ in the 12 period, and then remains stable. When SZ50 is affected by the impact from the futures market, it shows strong reaction; When SZ50 is affected by the impact of standard deviation from its own, the reaction immediately rises by $17.38 \%$, and then gradually falls.

3.7 Variance Decomposition. Under normal circumstances, the impulse response function is to capture the dynamic impact path of the impact of a variable on another variable, and the variance decomposition can decompose the variance of a variable in the VAR model to each disturbance. Thus the variance decomposition provides the relative degree of each disturbance factor affecting each variable of VAR model. A further quantitative analysis of the quantity of the respective role of SZIH and SZ50 in the process of price discovery is carried out in this paper, and the respective average market share is acquired by calculating the proportions of their respective fluctuations various, so as to quantify the role played in the process of price discovery by means of variance decomposition.

Table 3. Results of variance decomposition.

\begin{tabular}{lllll}
\hline \multirow{2}{*}{$\begin{array}{l}\text { Predictive } \\
\text { period }\end{array}$} & $\begin{array}{l}\text { Fluctuations } \\
(100)\end{array}$ & various of SZIH & Fluctuations various of SZ50 (100) \\
\cline { 2 - 5 } & From SZIH & From SZ50 & From SZIH & From SZ50 \\
\hline 1 & 100 & 0 & 86.48286 & 13.51714 \\
\hline 5 & 99.18469 & 0.815307 & 91.75202 & 8.247976 \\
\hline 10 & 97.69018 & 2.309816 & 92.56883 & 7.431168 \\
\hline 15 & 96.77637 & 3.223632 & 92.88361 & 7.116386 \\
\hline 20 & 96.24612 & 3.753882 & 93.04601 & 6.953989 \\
\hline 25 & 95.91897 & 4.081025 & 93.14274 & 6.857258 \\
\hline 30 & 95.70315 & 4.296845 & 93.20581 & 6.794194 \\
\hline
\end{tabular}

Table 3 is the predicted result of variance decomposition in the 30 periods of SZIH and SZ50. According to the results to this Table, it can be seen that the fluctuation of SZIH is mostly affected by its own, and the self explanatory contribution rate of the first period is $100 \%$ with regard to the variance decomposition of SZIH. With the extension of the predictive period, the self explanatory level of the futures market declines gradually and basically remains stable at about $95 \%$ to the 30 period, while the variance of the spot market accounted for about 4\%. With regard to the variance decomposition of SZ50, the contribution rate of the futures market in first period is $86.48 \%$, then gradually rises, and remains stable at $93 \%$ in the thirty period, while the self explanatory level of SZ50 declines gradually.

The effect degree and duration of SSE 50 stock index futures variations is stronger than that of $\mathrm{SSE} 50$ index variations. From this point of view, the futures market is the leader in price discovery has been further verified.

\section{Conclusion and Suggestion}

An empirical study on the relationship between SSE 50 stock index futures and stock index spot is carried out in this paper. The following conclusions are obtained: There is a long-term equilibrium relationship between SSE 50 stock index futures and stock index spot and stock index futures index is the Granger cause of the spot index, which means the futures index has a one-way effect on the spot index. The results show that although the launch time is short, the operation of SSE 50 stock index futures is effective in China and has reflected a better price discovery function.

The conclusion of this paper is of great significance to the investors and the government. The on-way effect of SSE 50 stock index futures price on SSE 50 index indicates that SSE 50 stock index futures will be ahead of stock index spot price in appearing turning-point. Investor can pre-judge the price turning-point of the stock index spot based on the price turning-point of the SSE 50 stock index futures and carry out reverse operation in advance to avoid risks and improve returns. Meanwhile the 
regulators can also adjust economic policies in a timely manner according to the variation of the SSE 50 stock index futures to avoid the spread of local financial risk.

China's futures market after thirty years of exploration has achieved good development, the function of the futures market has been shown, but stock index futures and stock index spot market regulations in China are still dominated by administrative means. SSE 50 index is not the Granger cause of SSE 50 stock index futures variation indicating that there is great room for the improvement of stock index futures and stock index spot market information transmission efficiency in China. In order to promote the operational efficiency of the stock index futures market in China, the regulation of the market should be transferred from administrative means to market means with more emphasis on the active regulation of the market, such as the implementation of the stock market $\mathrm{T}+0$ liquidation system and enhancing the information transfer between the spot market and ensuring the healthy development of the stock index futures market in China.

\section{References}

[1] Liu Qingfu and Hua Renhai, Risk transmission between stock index futures and stock index spot markets in China, Statistical Research, vol.28, pp. 84-90, 2011.

[2] Yang ruijie and Zhang Xiangli, The relationship between spot and futures prices in Chinese stock indices: a study based on price leadership, volatility leadership, and the absence of arbitrage, International Business, vol.2, pp. 89-100, 2016.

[3] Jian Yang, Zihui Yang, Yinggang Zhou, Intraday price discovery and volatility transmission in stock index and stock index futures markets, evidence from China, Journal of Futures Markets, vol.3, pp. 99-121, 2012.

[4] Fang Kuangnan and Cai Zhenzhong, Research on price discovery function of stock index futures in Chinese emerging market, Statistical Research, vol.29, pp. 73-78, 2012.

[5] Stoll. H. R. and Whaley, R. E, The dynamics of stock index and stock index futures returns, Journal of Financial and Quantitative Analysis, vol.25, pp. 441-468, 1990.

[6] Hsu. H. and Wang, J, Price expectation and the pricing of stock index futures, Review of Quantitative Finance and Accounting, vol.23, pp. 167-184, 2004.

[7] Butterworth. D. and Holmes. P, Ex ante hedging effectiveness of uk stock index futures contracts: evidence for the ftse 100 and ftse mid 250 contracts, European Financial Management, vol.6, pp. 441-457,2000.

[8] Xu Jinjian and Wu Haihua, Studies on the effect of stock index futures to underlying index volatility_ based on the Shanghai 50 stock index futures, Journal of Qingdao University, vol. 29, pp. 122-127, 2016. 